\title{
Article \\ Chemical Images on Fingerprints Revealed with Mass Spectrometry
}

\author{
Andrea Carrà $^{1}$, Luigi Falciola ${ }^{2,3} \mathbb{D}^{\mathbb{D}}$, Giuseppe Cappelletti ${ }^{2,3} \mathbb{D}^{\mathbb{D}}$, Lavinia Morosi ${ }^{4}$ and Enrico Davoli $^{1, *(\mathbb{D})}$ \\ 1 Department of Environmental Health Sciences, Istituto di Ricerche Farmacologiche Mario Negri IRCCS, \\ Via Mario Negri 2, 20156 Milan, Italy; andrea.carra@marionegri.it \\ 2 Dipartimento di Chimica, Università degli Studi di Milano, Via Golgi 19, 20133 Milan, Italy; \\ luigi.falciola@unimi.it (L.F.); giuseppe.cappelletti@unimi.it (G.C.) \\ 3 Consorzio Interuniversitario Nazionale per la Scienza e Tecnologia dei Materiali, (INSTM), Via Giusti 9, \\ 50121 Florence, Italy \\ 4 Istituto di Ricerche Farmacologiche Mario Negri IRCCS, IRCCS Humanitas Research Hospital, \\ Via Manzoni 56, Rozzano, 20089 Milan, Italy; lavinia.morosi@humanitasresearch.it \\ * Correspondence: enrico.davoli@marionegri.it; Tel.: +39-02-3901-4399; Fax: +39-02-3901-4735
}

Citation: Carrà, A.; Falciola, L.; Cappelletti, G.; Morosi, L.; Davoli, E. Chemical Images on Fingerprints Revealed with Mass Spectrometry. Appl. Sci. 2021, 11, 5624. https:// doi.org/10.3390/app11125624

Academic Editor: Cristian FOCSA

Received: 14 May 2021

Accepted: 15 June 2021

Published: 18 June 2021

Publisher's Note: MDPI stays neutral with regard to jurisdictional claims in published maps and institutional affiliations.

Copyright: (c) 2021 by the authors. Licensee MDPI, Basel, Switzerland. This article is an open access article distributed under the terms and conditions of the Creative Commons Attribution (CC BY) license (https:// creativecommons.org/licenses/by/ $4.0 /)$.
Featured Application: Reconstruction of chemical images of solid objects revealed in human fingerprints, using nanoparticles to assist MALDI imaging.

Abstract: Commercially available UV-adsorbent $\mathrm{TiO}_{2}$ nanoparticles were used to assist laser/desorption ionization in the course of matrix-assisted laser desorption ionization mass spectrometry imaging (MALDI-MSI). Titanium nano-powders proved extremely stable and efficient for small molecule ionization, with negligible background noise in the low mass region $(m / z<500 \mathrm{Da})$. Validation steps were carried out, assessing detection limits and comparing the results to those of the established DESI/Orbitrap technique. The new analytical method was used to reveal the molecular distribution of endogenous (lipids) and exogenous (analgesics and antipyretics) compounds in latent finger marks (LFMs). The detection limits of endogenous fatty acids and small molecules such as caffeine were in the range of $\mathrm{fmol} / \mathrm{mm}^{2}$ on LFMs. The technique separated overlapping latent finger marks, exploiting the differences in lipid expression of human skin. Finally, the method was used to prove contact between skin and objects contaminated by different substances, such as credit cards and paper clips, with chemical images that maintain the shape of the objects on the LFM.

Keywords: touch chemistry; latent finger marks; mass spectrometry imaging; drugs

\section{Introduction}

In recent decades, there have been many efforts to develop new analytical techniques for localizing and mapping trace compounds in biological samples. Mass spectrometry imaging (MSI) is one method of choice because it measures the chemical composition of a sample point by point.

In 1967, Liebl [1] reported the first MSI experiment regarding the characterization of some inorganic materials. Later, the combination of a laser probe with a time-of-flight (TOF) mass spectrometer was proposed by Hillenkamp et al. [2], exploiting the potential of the technique for organic materials. Although the laser ion source led to extremely localized ionization, the detection of big molecules remained an open task. To overcome that limitation, Karas et al. [3] and Tanaka et al. [4] reported that some specific UV-adsorbent compounds (matrix) can assist laser ionization, leading to a more efficient and versatile MS technique, called matrix-assisted laser desorption ionization (MALDI). Since 1997, MALDI-MSI has become one of the most popular techniques to investigate the distribution of big biomolecules in tissue sections due to the works of Caprioli et al. [5-7]. MALDI-MSI is currently used to investigate different samples, such as plant [8] and animal models [9]. 
Despite its high sensitivity and wide dynamic range, MALDI-MSI is not completely suitable for small molecule detection $(m / z<1000 \mathrm{Da})$, because of the strong background noise generated by the ion source decay of the matrix [10]. Consequently, other ionization techniques [11,12] have been used to assist MSI-applications; however, the lateral resolutions they achieve are not comparable to the superior optical resolution observed with laser ion sources.

An alternative approach to the MSI of small molecules is to use UV-absorbent inorganic nanomaterials instead of the conventional MALDI matrices [13-19]. The limiting aspects of this approach are the ad hoc synthesis required to produce nanomaterials, and their unknown shelf life and stability. As reported in the literature [20,21], metallic nanoparticles can undergo clusterization under laser irradiation. These side processes result in several interfering signals in the MS spectra. Commercially available oxide-based nanomaterials, with well-established physico-chemical properties and shelf lives, will overcome these issues [22].

Aside from biological applications of MALDI-MSI [23,24], this technique is innovative in many other research contexts. In the forensic field, for example, it has been used to detect latent fingermarks (LFMs) [25-27]. However, the analytical separation of overlapping LFMs and the detection of trace compounds embedded in human skin are still areas of debate $[20,28]$.

We developed a new method based on MALDI-MSI, starting with commercially available $\mathrm{TiO}_{2}$ nanoparticles (Evonik P25). The technique was used to identify the chemical distribution of small molecules embedded in LFMs. The detection of endogenous compounds (e.g., lipids) was used to distinguish overlapping fingerprints from different donors. Exogenous compounds were also detected, proving direct and secondary interactions between skin and potentially illicit substances.

\section{Materials and Methods}

A MALDI 4800 TOF-TOF (AB SCIEX, Old Connecticut Path, Framingham, MA 01701, USA) was used. The instrument worked in reflectron mode, achieving a resolving power (RP) of 25,000 and a mass accuracy (MA) of $50 \mathrm{ppm}$. The ion source was equipped with a $355 \mathrm{~nm}$ Nd:YAG laser ( $200 \mathrm{~Hz}$ repetition rate) and operated under a vacuum $(0.7 \mu \mathrm{Torr})$ The optics were oriented to focus the laser beam $(50 \mu \mathrm{m})$ orthogonally on the target, obtaining an energy density of $500-1000 \mathrm{eV} / \mathrm{mm}^{2}$. Ions were extracted and accelerated by applying a high-voltage pulse $(20 \mathrm{kV})$ after a predetermined time delay of $0.35 \mathrm{~ms}$. The spectrometer digitalized data every $2 \mathrm{~ns}$, averaging one spectrum every four laser shots. The electron multiplier was set to $0.85 \mathrm{~V}$. The instrument was controlled by software with a 4000-Series SCIEX Explorer.

Before any experiment, the instrument was tuned with a CAL-MIX5 and MALDI methodology was optimized using caffeine and stearic acid as reference standards for positive and negative ion modes. A matrix suspension of a photoactive matrix (Evonik P25 $\left.\mathrm{TiO}_{2}, 0.5 \mu \mathrm{g} / \mu \mathrm{L}\right)$ was prepared using $\mathrm{H}_{2} \mathrm{O}$ and $\mathrm{CH}_{3} \mathrm{OH}(75: 25 \mathrm{v} / \mathrm{v})$. Approximately $1 \mu \mathrm{L}$ of $\mathrm{TiO}_{2}$ suspension was drop-cast on the laser target, which was then dried upside-down for $2 \mathrm{~h}$ to ensure even $\mathrm{TiO}_{2}$ coverage. In this way, the MALDI target was functionalized with the nano-material. Finally, $1 \mu \mathrm{L}$ of each reference standard was deposited on the $\mathrm{TiO}_{2}$ spot.

The limits of detection (LODs) were assessed in positive and negative ion modes, reducing the amounts of calibrants spotted on the MALDI target. Assuming an S/N ratio equal to 3 , the LODs were estimated as $400 \mathrm{fmol} / \mathrm{mm}^{2}$ for caffeine (positive ion mode) and $250 \mathrm{fmol} / \mathrm{mm}^{2}$ for stearic acid (negative ion mode). The relative spectra are shown in Figure S1.

The imaging experiment on endogenous compounds in LSM started with a donor who touched the MALDI target with the index finger. Approximately $2 \mathrm{mg}$ of $\mathrm{TiO}_{2}$ nanoparticles were spread on the target. Some nanoparticles were trapped in the LFM, but the excess nanomaterial was carefully removed under a gentle nitrogen stream. The mass spectrometer was set up in order to collect each pixel using 10 individual laser shoots. The 
molecular distribution of the analytes was determined by recording a pixel every $30 \mu \mathrm{m}$. Acquisition occurred in negative ion mode, revealing skin fatty acids. The shooting rate was approximately 104 laser shoots per $\mathrm{mm}^{2}$. Time to digital converter (TDC) was set to $4 \mathrm{~ns} /$ bin for data storage. Dedicated software (BioMap, Novartis) was used to merge all the spectra, leading to the final chemical image. Attribution of the MS signals was based on accurate mass measurements and confirmed by analyzing the same sample with an LTQ/Orbitrap (Thermo Fisher Scientific, San Jose, CA, USA) mass analyzer, equipped with a DESI ion source (Prosolia, Indianapolis, IN, USA). The LTQ/Orbitrap operated at a resolution of 100,000, achieving a 5 ppm mass accuracy.

The imaging experiment of exogenous compounds used most of the instrumental conditions reported above. An over-the-counter drug (formulation: acetaminophen, aspirin, and caffeine) was used. The experiment started by asking a subject to touch the drug tablet with their finger and then deposit the fingerprint on the MALDI target. Approximately $2 \mathrm{mg}$ of $\mathrm{TiO}_{2}$ was spread on the target, revealing the LMFs. Images were acquired in positive reflectron ion mode, revealing traces of target compounds embedded in human skin.

\section{Results}

\section{1. $\mathrm{TiO}_{2}$-Based MALDI Matrix}

Figure 1 compares the performances of $\mathrm{CHCA}$ and $\mathrm{NP} \mathrm{TiO}_{2}$ using caffeine as a reference standard. Pristine P25 always assists the generation of $\mathrm{Na}$ and $\mathrm{K}$ molecular adducts in the course of laser ionization (Figure 1B). This process can be enhanced by saturating the surface of $\mathrm{P} 25$ with protons or specific cations $\left(\mathrm{Li}^{+}, \mathrm{Na}^{+}\right.$, and $\left.\mathrm{K}^{+}\right)$. Doped P25 NP can modulate the ionization mechanism, driving it toward the cationization of interest (Figure S2).
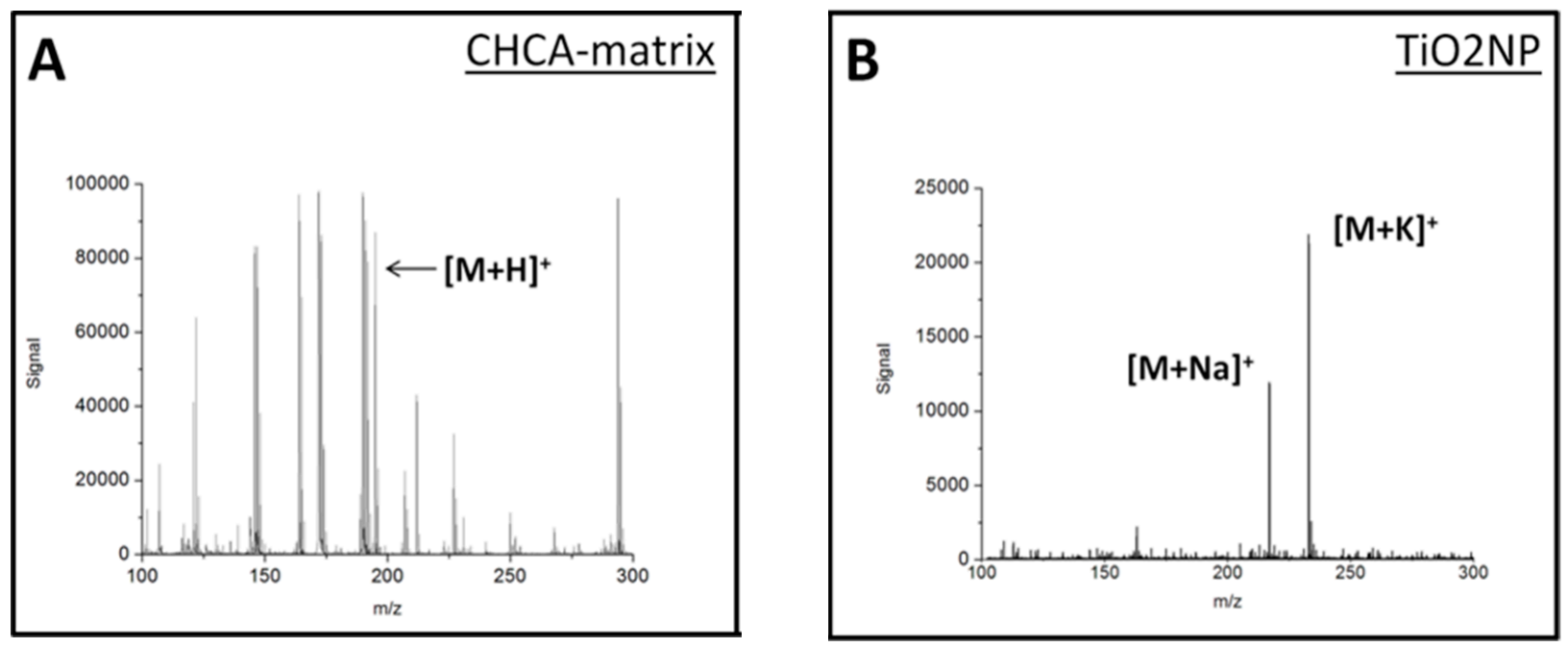

Figure 1. Caffeine on target. CHCA matrix (A) vs. $\mathrm{TiO}_{2} \mathrm{NP}(\mathbf{B})$. On the MALDI target, $1 \mu \mathrm{L}$ of nanoparticle suspension was drop-cast $(0.5 \mathrm{mg} / \mathrm{mL}, 0.5 \mu \mathrm{g}$ spotted $)$ and $2.5 \mathrm{nmol}$ of caffeine $(1 \mu \mathrm{L}, 2.5 \mathrm{mM}$ water solution) was added. The mass spectrum in (A) is dominated by matrix ions in the low mass range, while nanoparticles in (B) produce a cleaner spectrum, favoring cationization over protonation.

\subsection{Endogenous Compounds MSI}

An ion at $m / z 265.1420$ was observed in all fingerprints acquired. From the DESI/Orbitrap measurement, this signal was identified as the dodecyl sulfate anion of SDS, a surfactant usually employed in cleaning formulations. This ion was used as an instrumental reference (lock mass, red signal in Figure 2) in LFM-analysis, achieving high mass accuracy, even with regular TOF mass detectors (resolution lower than 20,000). 


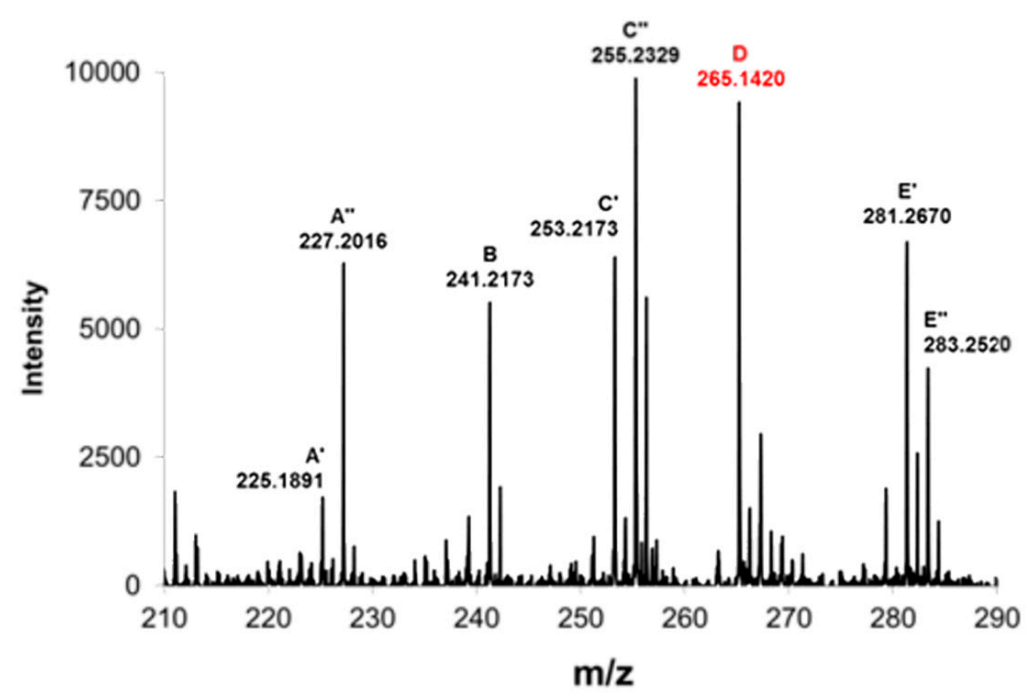

Figure 2. Endogenous compounds in LFMs: both saturated and unsaturated fatty acids (Table S1) were identified as $[\mathrm{M}-\mathrm{H}]^{-}$deprotonated molecular ions, based on the high resolution spectra. The ion at $m / z 265.1420$ marked in red is a ubiquitous trace compound on the human skin, SDS, and was used as the instrumental reference.

Five different LFM reconstructions, obtained by MALDI-MSI, are shown in Figure 3; Figure 3A-D depicts palmitoleic, palmitic, oleic, and stearic acids, respectively. Figure 3E is the chemical image obtained by mapping the relative abundance of SDS anions.
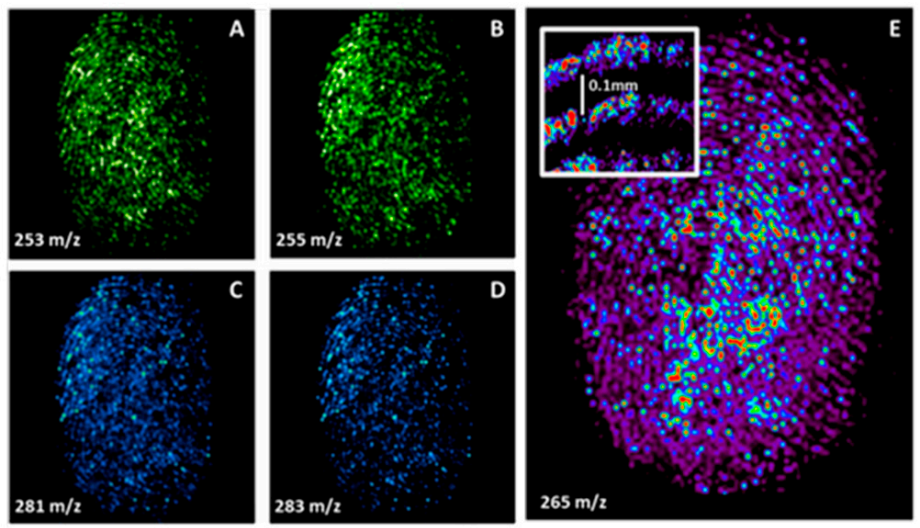

Figure 3. Endogenous compounds in LFMs. (A-D) Palmitoleic, palmitic, oleic, and stearic acids, respectively. (E) The distribution in negative ion mode of SDS.

Figure 4 shows the experimental case of two overlapped LFMs. Two different people touched the MALDI target after a short time, and P25 was then used for MALDI imaging. Figure $4 \mathrm{~A}$ is the optical image of both LFMs, obtained with an optical stereoscope equipped with a $2 \times$ camera. Figure $4 \mathrm{~B}$ shows the LFMs reconstruction obtained by extracting the signal due to SDS $\left(\mathrm{C}_{12} \mathrm{H}_{25} \mathrm{SO}_{4}, m / z 265\right.$, blue) from the MSI dataset. Figure $4 \mathrm{C}$, D shows the molecular distribution of myristic acid $\left(\mathrm{C}_{14} \mathrm{H}_{28} \mathrm{O}_{2}, m / z 227\right.$, green) and arachidic acid $\left(\mathrm{C}_{20} \mathrm{H}_{40} \mathrm{O}_{2}, m / z 311\right.$, red), respectively. These fatty acids were expressed differently in the two donors, so their relative abundance allowed the full deconvolution of both LFMs. Figure $4 \mathrm{E}$ is an example of a background chemical image obtained by extracting an unidentified recurring ion $(m / z 65$, grey) from the background noise. This MSI excludes the presence of artifacts or false positives in the LFM reconstruction. 

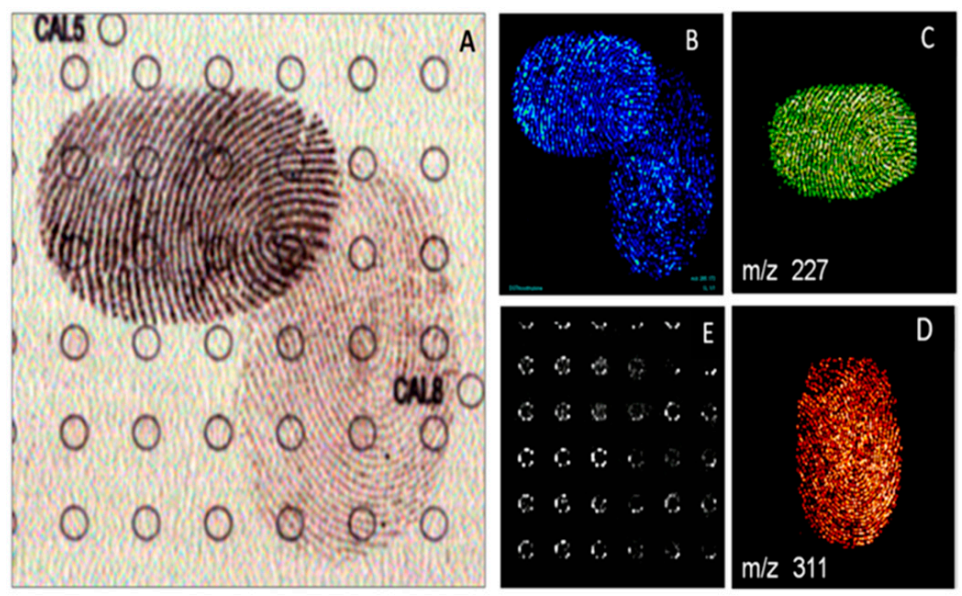

Figure 4. Optical image of fingermarks from different persons (A) shows several common ions ((B) an image from an unidentified common ion) but can be fully resolved using different intensities of fatty acids. (C) Image of $m / z 227$, probable identification myristic acid; (D) image of $m / z$ 312, probable identification arachidic acid; and (E) a background ion. Full mass spectra of fingermarks are reported in Figure S1.

\subsection{Exogenous Compounds MSI}

MSI detected and imaged the principal constituents of a tablet (Table S2. All components were cationized by $\mathrm{P} 25$, leading to $[\mathrm{M}+\mathrm{Na}]^{+}$and $[\mathrm{M}+\mathrm{K}]^{+}$molecular ions. In this case too, the presence of the analytes was confirmed with DESI/Orbitrap: acetaminophen and caffeine in positive ion mode and acetylsalicylic acid in negative ion mode ([M-H] ${ }^{-}$ $m / z$ 179.0342) (data not shown).

Figure 5 shows the contact regions between the skin and a tablet. Figure $5 \mathrm{~A}, \mathrm{~B}$ describes the relative abundance of the first tablet constituent, acetaminophen, on the skin. These molecular distributions were revealed by extracting (in green) the relative abundance of the ions $[\mathrm{M}+\mathrm{Na}]^{+} m / z 174$ and $[\mathrm{M}+\mathrm{K}]^{+} m / z$ 190. Similarly, Figure 5C,D maps in blues the distribution of the second constituents (acetylsalicylic acid, $[\mathrm{M}+\mathrm{Na}]^{+} m / z 203$ and $[\mathrm{M}+\mathrm{K}]^{+}$ $m / z 219)$.

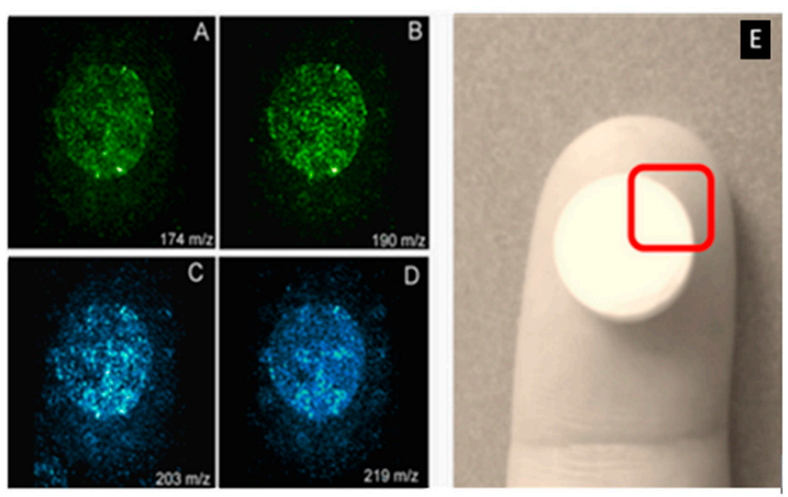

Figure 5. Exogenous compounds in LFM: (A,B) acetaminophen and (C,D) acetylsalicylic acid. The shape of the object, one round tablet, leaves chemical images that can be seen on the LFM (E).

To demonstrate the ability of this technique to assess the transposition of a trace compound through several objects, a paper clip was stored in the tablet bottle, picked up with tweezers, and swiped along with the donor finger. Despite the very low concentration of the analytes (lower than the LOD) and the general complexity of drug imaging [29], the MSI method was sensitive enough to highlight the region of contact between the clip and skin (Figure 6). The strong and close contact with the skin can produce a sort of 
template effect of the tablet on the skin, similar to the effect of typebars on the ribbon in an old typewriter.
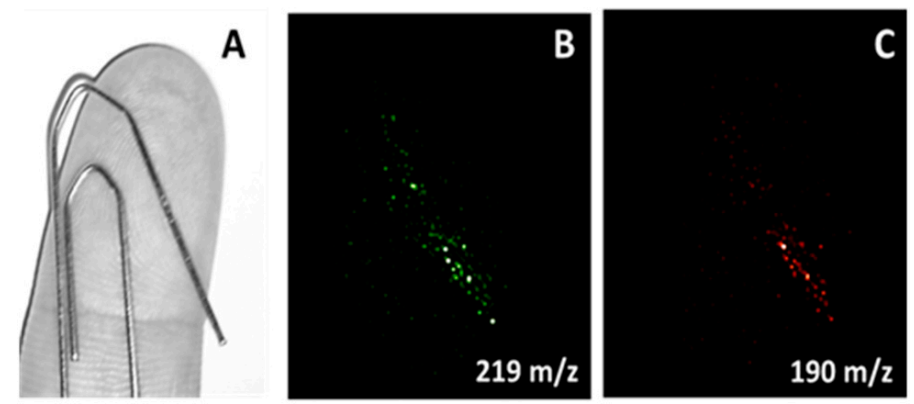

Figure 6. Exogenous compounds in LFM. The chemical image of the fingerprint retains the details of the object touched with the finger. (A) Optical image; $(\mathbf{B}, \mathbf{C})$ acetyl salicylate and acetaminophen chemical images on the LFM, respectively.

Figure 7 depicts an ad hoc MSI experiment, showing that the engraving of the capital letter $\mathrm{E}$ on the tablet resulted in a molecular print of the letter on human skin, which could be revealed by extracting one of the diagnostic ions from the LFM.
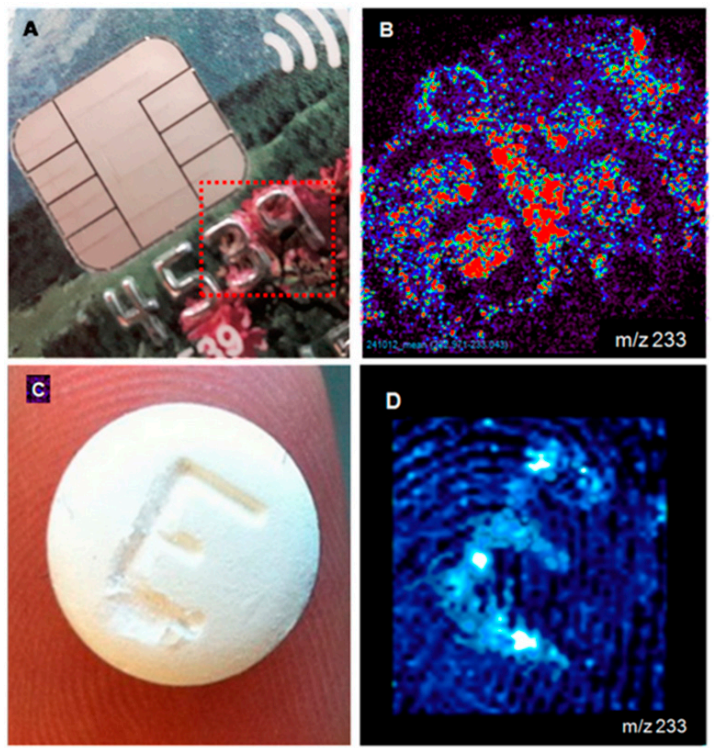

Figure 7. Details of chemical images on fingermarks from different objects. Caffeine residues on a credit card contaminated with it (A), and from a tablet (C), are visible on fingermarks (B,D), preserving the details of the object touched. MS images were flipped horizontally for clarity.

This chemical image originated from the residuals of the powder trapped in the groove and proved that the morphology of the object can influence the molecular distribution of specific analytes along the skin (acetaminophen, $[\mathrm{M}+\mathrm{Na}]^{+} \mathrm{m} / z$ 190).

Images of objects over the LFM resemble not only the shape of the object but also its surface (Figure 7). A credit card, with embossed numbers rising above the surface of the card, produced a negative image. A tablet with an imprinted E produced a positive image of the surface. A possible explanation is that the tops of the embossed numbers on the credit card retained fewer particles, leaving more contamination around and between numbers due to less mechanical wiping out related to contact with other objects. Conversely, caffeine traces were trapped inside the groove of a tablet (Figure 7C,D). 


\section{Discussions}

The chemical imaging techniques discussed here, taking advantage of the low chemical noise from the matrix, allow low molecular weight imaging at high sensitivity.

One of the main features that makes P25 suitable for MSI is the ability to absorb the Nd-YAG emission wavelength ( $\lambda 355 \mathrm{~nm}$, Figure S3). In addition to the classical properties of nanomaterials (average size, surface area, and relative porosity [30]), the P25 amphiprotic surface (isoelectric point around 6.0, typical of this oxide [31,32], Figure S4) allows the modulation of the adsorption of different kinds of organic analytes [33-37]. Moreover, the high surface area of the nanoparticles can easily exchange the surface cations, allowing for a controlled cationization process, assisting ionization [15].

We compared the thermochemical properties of P25 to the conventional $\alpha$-cyano4-hydroxycinnamic acid (CHCA) MALDI matrix. P25's high melting point and sublimation enthalpy (one order of magnitude higher than CHCA $[38,39]$ ) minimize the selfdecomposition induced by the laser irradiation, leading to negligible background noise in the low-mass region of the spectra. Its intrinsic chemical stability means P25 can assist the Nd-YAG laser source in the desorption/ionization process without decomposing or interfering with the MS analysis [40].

Untargeted analysis revealed endogenous compounds in LFMs: both saturated and unsaturated fatty acids (Table S1 and Figures 2 and S5) were recognized as $[\mathrm{M}-\mathrm{H}]^{-}$molecular ions. The signal's attribution was confirmed by analyzing the same sample with DESI/Orbitrap, operating in negative ion mode.

One of the most important features in the chemical images is the strong lateral resolution, achieved by working with NP that allow for reconstructing the fine structures of the skin, determining the relative abundance of each analyte point-by-point over the skin. In summary, P25 offers an extremely localized ionization process, with good sensitivity for trace compounds. These are the two key points to use MALDI imaging to separate overlapping fingermarks, resulting from the interaction of the same object (MALDI target) with different subjects. Overlapped LFMs provide critical forensic evidence because of their controversial legal validity. MSI can selectively highlight each fingerprint according to the different expressions of lipids on the skin, thus enabling MSI to completely distinguish multiple overlapped LFMs.

\section{Conclusions}

The analysis of small molecules with inorganic NPs, has been described as a powerful alternative to conventional matrices for latent fingerprints [18,41]. All our experimental evidence indicated that commercially available P25 nanoparticles assist the ionization of small molecules in MSI experiments. The strong thermochemical stability of $\mathrm{TiO}_{2}$ under laser irradiation resulted in negligible background noise in the low mass region $(m / z<500)$.

Based on these results, proof of concept of an innovative method using MALDI-MSI was developed. This new MSI method is suitable for the deconvolution of overlapping latent finger marks and sensitive enough to reveal exogenous trace compounds embedded in human skin. We also showed that, with the high sensitivity of this approach, one can image not only endogenous compounds but also residues of exogenous compounds on LFM. These chemical images can prove the contact between the finger and tablet, and the chemical images reflected the shape of the contaminated object (paper clip).

Thus, MALDI-MSI may be a practical analytical approach useful to support the forensic application of mass spectrometry. This approach, to the best of our knowledge, is the first demonstration of visualization by mass spectrometry of chemical images of exogenous compounds on human skin, with high sensitivity and direct analytical abilities.

Future developments will be devoted to increasing the ionization efficiency of P25, using UV photo-adsorber compounds and plasmon resonance nanostructures. 
Supplementary Materials: The following are available online at https:/ /www.mdpi.com/article/ 10.3390/app11125624/s1. Figure S1: NP MALDI/TOF analysis of caffeine $\left([\mathrm{M}+\mathrm{Na}]^{+} \mathrm{m} / \mathrm{z} 217\right.$, $\left.[\mathrm{M}+\mathrm{K}]^{+} \mathrm{m} / \mathrm{z} 233\right)$ and stearic acid $\left([\mathrm{M}-\mathrm{H}]^{-} \mathrm{m} / \mathrm{z} 283\right)$. MS spectra of caffeine: A $\left(160 \mathrm{pmol} / \mathrm{mm}^{2}\right), \mathrm{B}$ $\left(16.0 \mathrm{pmol} / \mathrm{mm}^{2}\right)$, and C $\left(1.60 \mathrm{pmol} / \mathrm{mm}^{2}\right)$; MS spectra of stearic acid in box-D $\left(111 \mathrm{pmol} / \mathrm{mm}^{2}\right)$, box-E (11.1 pmol $\left./ \mathrm{mm}^{2}\right)$, and box-F $\left(1.11 \mathrm{pmol} / \mathrm{mm}^{2}\right)$. Figure S2. NP MALDI/TOF measurements of caffeine $10 \mathrm{pmol} / \mathrm{mm}^{2}$. (A) caffeine ionized by $\mathrm{P} 25 \mathrm{H}$-doped $\left([\mathrm{M}+\mathrm{H}]^{+} \mathrm{m} / \mathrm{z} 195\right)$, (B) caffeine ionized by P25 Li-doped ([M+Li] $]^{+} m / z$ 201), C caffeine ionized by P25 Na-doped $\left([\mathrm{M}+\mathrm{Na}]^{+} \mathrm{m} / z\right.$ 217), and D caffeine ionized by P25 K-doped $\left([\mathrm{M}+\mathrm{K}]^{+} \mathrm{m} / z\right.$ 233). Figure S3. Diffuse reflectance spectrum of P25 sample. Figure S4. $\zeta$ potential vs. pH of P25 aqueous slurry. Figure S5. MALDI/TOF full mass spectrum of a fingermark showing different fatty acids (probable structures, see Table S1 for identification) and different images created on six analytes. Table S1. Probable structures of endogenous substances (fatty acids) revealed in latent fingermarks by NP MALDI/TOF and DESI/Orbitrap experiments. Table S2. Exogenous substances (caffeine, acetaminophen and acetyl salicylic acid) revealed in latent fingermarks by MALDI/TOF and DESI/Orbitrap.

Author Contributions: Conceptualization, A.C., E.D., L.F. and G.C.; methodology, A.C. and L.M.; formal analysis, A.C. and L.M.; writing-original draft preparation, A.C. and E.D.; writing-review and editing, all authors; supervision, E.D.; funding acquisition, E.D. All authors have read and agreed to the published version of the manuscript.

Funding: This work was supported by Cariplo Foundation for the project "Nanostructured-initiators for matrix-free, surface-based mass spectrometry imaging of antitumour drugs in tissues" (Project 2013-0692) to E.D.

Institutional Review Board Statement: Not applicable.

Informed Consent Statement: Not applicable.

Data Availability Statement: Data is contained within the article or supplementary material.

Acknowledgments: This work was supported by Cariplo Foundation for the project "Nanostructuredinitiators for matrix-free, surface-based mass spectrometry imaging of antitumour drugs in tissues" (Project 2013-0692). The authors wish to thank J.D. Baggott for editorial assistance.

Conflicts of Interest: The authors declare no conflict of interest. The funders had no role in the design of the study; in the collection, analyses, or interpretation of data, in writing the manuscript, or in the decision to publish the results.

\section{References}

1. Liebl, H. Ion Microprobe Mass Analyzer. J. Appl. Phys. 1967, 38, 5277-5283. [CrossRef]

2. Hillenkamp, F.; UNSöLD, E.; Kaufmann, R.; Nitsche, R. Laser Microprobe Mass Analysis of Organic Materials. Nature 1975, 256, 119-120. [CrossRef] [PubMed]

3. Karas, M.; Bachmann, D.; Hillenkamp, F. Influence of the Wavelength in High-Irradiance Ultraviolet Laser Desorption Mass Spectrometry of Organic Molecules. Anal. Chem. 1985, 57, 2935-2939. [CrossRef]

4. Tanaka, K.; Waki, H.; Ido, Y.; Akita, S.; Yoshida, Y.; Yoshida, T.; Matsuo, T. Protein and Polymer Analyses up To m/z 100000 by Laser Ionization Time-of-Flight Mass Spectrometry. Rapid Commun. Mass Spectrom. 1988, 2, 151-153. [CrossRef]

5. Caprioli, R.M.; Farmer, T.B.; Gile, J. Molecular Imaging of Biological Samples: Localization of Peptides and Proteins Using MALDI-TOF MS. Anal. Chem. 1997, 69, 4751-4760. [CrossRef] [PubMed]

6. Chaurand, P.; Stoeckli, M.; Caprioli, R.M. Direct Profiling of Proteins in Biological Tissue Sections by MALDI Mass Spectrometry. Anal. Chem. 1999, 71, 5263-5270. [CrossRef] [PubMed]

7. Stoeckli, M.; Chaurand, P.; Hallahan, D.E.; Caprioli, R.M. Imaging Mass Spectrometry: A New Technology for the Analysis of Protein Expression in Mammalian Tissues. Nat. Med. 2001, 7, 493-496. [CrossRef] [PubMed]

8. Lee, Y.J.; Perdian, D.C.; Song, Z.; Yeung, E.S.; Nikolau, B.J. Use of Mass Spectrometry for Imaging Metabolites in Plants: Mass Spectrometry for Imaging Metabolites in Plants. Plant J. 2012, 70, 81-95. [CrossRef]

9. Addie, R.D.; Balluff, B.; Bovée, J.V.M.G.; Morreau, H.; McDonnell, L.A. Current State and Future Challenges of Mass Spectrometry Imaging for Clinical Research. Anal. Chem. 2015, 87, 6426-6433. [CrossRef]

10. Byrd, H.C.M.; McEwen, C.N. The Limitations of MALDI-TOF Mass Spectrometry in the Analysis of Wide Polydisperse Polymers. Anal. Chem. 2000, 72, 4568-4576. [CrossRef]

11. Balog, J.; Sasi-Szabo, L.; Kinross, J.; Lewis, M.R.; Muirhead, L.J.; Veselkov, K.; Mirnezami, R.; Dezso, B.; Damjanovich, L.; Darzi, A.; et al. Intraoperative Tissue Identification Using Rapid Evaporative Ionization Mass Spectrometry. Sci. Transl. Med. 2013, 5, 194ra93. [CrossRef] [PubMed] 
12. Eberlin, L.S.; Norton, I.; Dill, A.L.; Golby, A.J.; Ligon, K.L.; Santagata, S.; Cooks, R.G.; Agar, N.Y.R. Classifying Human Brain Tumors by Lipid Imaging with Mass Spectrometry. Cancer Res. 2012, 72, 645-654. [CrossRef]

13. Taira, S.; Sugiura, Y.; Moritake, S.; Shimma, S.; Ichiyanagi, Y.; Setou, M. Nanoparticle-Assisted Laser Desorption/Ionization Based Mass Imaging with Cellular Resolution. Anal. Chem. 2008, 80, 4761-4766. [CrossRef] [PubMed]

14. Huh, Y.-M.; Jun, Y.; Song, H.-T.; Kim, S.; Choi, J.; Lee, J.-H.; Yoon, S.; Kim, K.-S.; Shin, J.-S.; Suh, J.-S.; et al. In Vivo Magnetic Resonance Detection of Cancer by Using Multifunctional Magnetic Nanocrystals. J. Am. Chem. Soc. 2005, 127, 12387-12391. [CrossRef] [PubMed]

15. Giordano, S.; Pifferi, V.; Morosi, L.; Morelli, M.; Falciola, L.; Cappelletti, G.; Visentin, S.; Licandro, S.A.; Frapolli, R.; Zucchetti, M.; et al. A Nanostructured Matrices Assessment to Study Drug Distribution in Solid Tumor Tissues by Mass Spectrometry Imaging. Nanomaterials 2017, 7, 71. [CrossRef]

16. Arendowski, A.; Ossoliński, K.; Niziol, J.; Ruman, T. Screening of Urinary Renal Cancer Metabolic Biomarkers with Gold Nanoparticles-Assisted Laser Desorption/Ionization Mass Spectrometry. Anal. Sci. 2020, 36, 1521-1527. [CrossRef] [PubMed]

17. Kratochvíl, J.; Prysiazhnyi, V.; Dyčka, F.; Kylián, O.; Kúš, P.; Sezemský, P.; Štěrba, J.; Straňák, V. Gas Aggregated Ag Nanoparticles as the Inorganic Matrix for Laser Desorption/Ionization Mass Spectrometry. Appl. Surf. Sci. 2021, 541, 148469. [CrossRef]

18. Amin, M.O.; Madkour, M.; Al-Hetlani, E. Metal Oxide Nanoparticles for Latent Fingerprint Visualization and Analysis of Small Drug Molecules Using Surface-Assisted Laser Desorption/Ionization Mass Spectrometry. Anal. Bioanal. Chem. 2018, 410, 4815-4827. [CrossRef]

19. Wu, Q.; Chu, J.L.; Rubakhin, S.S.; Gillette, M.U.; Sweedler, J.V. Dopamine-Modified $\mathrm{TiO}_{2}$ Monolith-Assisted LDI MS Imaging for Simultaneous Localization of Small Metabolites and Lipids in Mouse Brain Tissue with Enhanced Detection Selectivity and Sensitivity. Chem. Sci. 2017, 8, 3926-3938. [CrossRef] [PubMed]

20. McLean, J.A.; Stumpo, K.A.; Russell, D.H. Size-Selected (2-10 Nm) Gold Nanoparticles for Matrix Assisted Laser Desorption Ionization of Peptides. J. Am. Chem. Soc. 2005, 127, 5304-5305. [CrossRef] [PubMed]

21. Sekuła, J.; Nizioł, J.; Rode, W.; Ruman, T. Gold Nanoparticle-Enhanced Target (AuNPET) as Universal Solution for Laser Desorption/Ionization Mass Spectrometry Analysis and Imaging of Low Molecular Weight Compounds. Anal. Chim. Acta 2015, 875, 61-72. [CrossRef]

22. Morosi, L.; Spinelli, P.; Zucchetti, M.; Pretto, F.; Carrà, A.; D’Incalci, M.; Giavazzi, R.; Davoli, E. Determination of Paclitaxel Distribution in Solid Tumors by Nano-Particle Assisted Laser Desorption Ionization Mass Spectrometry Imaging. PLoS ONE 2013, 8, e72532. [CrossRef]

23. Chughtai, K.; Heeren, R.M.A. Mass Spectrometric Imaging for Biomedical Tissue Analysis. Chem. Rev. 2010, 110, 3237-3277. [CrossRef]

24. Morosi, L.; Matteo, C.; Ceruti, T.; Giordano, S.; Ponzo, M.; Frapolli, R.; Zucchetti, M.; Davoli, E.; D’Incalci, M.; Ubezio, P. Quantitative Determination of Niraparib and Olaparib Tumor Distribution by Mass Spectrometry Imaging. Int. J. Biol. Sci. 2020, 16, 1363-1375. [CrossRef] [PubMed]

25. Gao, D.; Li, F.; Song, J.; Xu, X.; Zhang, Q.; Niu, L. One Step to Detect the Latent Fingermarks with Gold Nanoparticles. Talanta 2009, 80, 479-483. [CrossRef]

26. Lim, C.S.; Chua, C.K.; Pumera, M. Detection of Biomarkers with Graphene Nanoplatelets and Nanoribbons. Analyst 2014, 139, 1072. [CrossRef] [PubMed]

27. Bailey, M.J.; Bradshaw, R.; Francese, S.; Salter, T.L.; Costa, C.; Ismail, M.; Webb, P.R.; Bosman, I.; Wolff, K.; de Puit, M. Rapid Detection of Cocaine, Benzoylecgonine and Methylecgonine in Fingerprints Using Surface Mass Spectrometry. Analyst 2015, 140, 6254-6259. [CrossRef] [PubMed]

28. Bradshaw, R.; Rao, W.; Wolstenholme, R.; Clench, M.R.; Bleay, S.; Francese, S. Separation of Overlapping Fingermarks by Matrix Assisted Laser Desorption Ionisation Mass Spectrometry Imaging. Forensic Sci. Int. 2012, 222, 318-326. [CrossRef]

29. Morosi, L.; Zucchetti, M.; D’Incalci, M.; Davoli, E. Imaging Mass Spectrometry: Challenges in Visualization of Drug Distribution in Solid Tumors. Curr. Opin. Pharmacol. 2013, 13, 807-812. [CrossRef] [PubMed]

30. Nalwa, H.S. (Ed.) Encyclopedia of Nanoscience and Nanotechnology. v. 1-10; American Scientific Publishers: Stevenson Ranch, CA, USA, 2004; Volume 10, ISBN 978-1-58883-001-2.

31. Oliva, F.Y; Avalle, L.B.; Cámara, O.R.; De Pauli, C.P. Adsorption of Human Serum Albumin (HSA) onto Colloidal TiO 2 Particles, Part I. J. Colloid Interface Sci. 2003, 261, 299-311. [CrossRef]

32. Kosmulski, M. Compilation of PZC and IEP of Sparingly Soluble Metal Oxides and Hydroxides from Literature. Adv. Colloid Interface Sci. 2009, 152, 14-25. [CrossRef] [PubMed]

33. Cappelletti, G.; Pifferi, V.; Mostoni, S.; Falciola, L.; Di Bari, C.; Spadavecchia, F.; Meroni, D.; Davoli, E.; Ardizzone, S. Hazardous O-Toluidine Mineralization by Photocatalytic Bismuth Doped ZnO Slurries. Chem. Commun. 2015, 51, 10459-10462. [CrossRef] [PubMed]

34. Soliveri, G.; Pifferi, V.; Panzarasa, G.; Ardizzone, S.; Cappelletti, G.; Meroni, D.; Sparnacci, K.; Falciola, L. Self-Cleaning Properties in Engineered Sensors for Dopamine Electroanalytical Detection. Analyst 2015, 140, 1486-1494. [CrossRef] [PubMed]

35. Le, Q.-C.; Ropers, M.-H.; Terrisse, H.; Humbert, B. Interactions between Phospholipids and Titanium Dioxide Particles. Colloids Surf. B Biointerfaces 2014, 123, 150-157. [CrossRef]

36. Teixeira, S.; Gurke, R.; Eckert, H.; Kühn, K.; Fauler, J.; Cuniberti, G. Photocatalytic Degradation of Pharmaceuticals Present in Conventional Treated Wastewater by Nanoparticle Suspensions. J. Environ. Chem. Eng. 2016, 4, 287-292. [CrossRef] 
37. Pargoletti, E.; Pifferi, V.; Falciola, L.; Facchinetti, G.; Re Depaolini, A.; Davoli, E.; Marelli, M.; Cappelletti, G. A Detailed Investigation of $\mathrm{MnO}_{2}$ Nanorods to Be Grown onto Activated Carbon. High Efficiency towards Aqueous Methyl Orange Adsorption/Degradation. Appl. Surf. Sci. 2019, 472, 118-126. [CrossRef]

38. Price, D.M.; Bashir, S.; Derrick, P.R. Sublimation Properties of x,y-Dihydroxybenzoic Acid Isomers as Model Matrix Assisted Laser Desorption Ionisation (MALDI) Matrices. Thermochim. Acta 1999, 327, 167-171. [CrossRef]

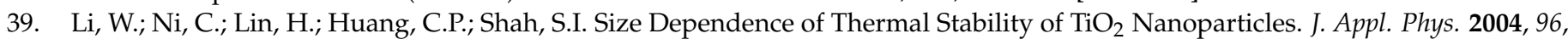
6663-6668. [CrossRef]

40. Schmidt, C.M.; Buchbinder, A.M.; Weitz, E.; Geiger, F.M. Photochemistry of the Indoor Air Pollutant Acetone on Degussa P25 $\mathrm{TiO}_{2}$ Studied by Chemical Ionization Mass Spectrometry. J. Phys. Chem. A 2007, 111, 13023-13031. [CrossRef] [PubMed]

41. Carra, A.; Cappelletti, G.; Falciola, L.; Davoli, E. Proceedings of the 60th ASMS Conference on Mass Spectrometry and Allied Topics, Vanvouver, BC, Canada, 20-24 May 2012. 